\title{
A Framework to Motivate Students in Choosing Their Future Medical School
}

\author{
Abdulraheem Alshareef \\ Department of Medical Laboratories Technology, College of Applied Medical Sciences, Taibah University, Madinah, Saudi Arabia
}

Received September 16, 2020; Revised October 22, 2020; Accepted November 29, 2020

\section{Cite This Paper in the following Citation Styles}

(a): [1] Abdulraheem Alshareef , "A Framework to Motivate Students in Choosing Their Future Medical School," Universal Journal of Educational Research, Vol. 8, No. 12, pp. 6778 - 6782, 2020. DOI: 10.13189/ujer.2020.081243.

(b): Abdulraheem Alshareef (2020). A Framework to Motivate Students in Choosing Their Future Medical School. Universal Journal of Educational Research, 8(12), 6778 - 6782. DOI: 10.13189/ujer.2020.081243.

Copyright $\odot 2020$ by authors, all rights reserved. Authors agree that this article remains permanently open access under the terms of the Creative Commons Attribution License 4.0 International License

\begin{abstract}
In recent years, the number of universities in the Saudi Arabian education industry, both government and private, has been steadily increasing. Saudi Arabia accounts for the majority of universities in the Middle East and North African region. By 2030, the number is expected to continue to climb with improved ranking of existing educational institutions and the arrival of new universities, including renowned international universities. Technology schools and medical schools are the two largest segments of the current education industry in Saudi Arabia. There are numerous competitors in these two fields, including schools in government, private, and international universities. It is widely acknowledged that universities with excellent customer value will attract excellent students. The aim of this study was to look into whether students can be motivated to choose their future institute if customer value principles from the business sector were implemented. Using Porter's five-forces analysis, this study developed a framework to motivate students' choices among various medical schools. The Balanced Scorecard model was used to establish a sustainable growth rate. The study concludes that customer value in the education industry, especially in universities, should be improved and included as a key performance indicator for schools and universities. Implementing excellent strategies to improve customer value will positively impact the education industry.
\end{abstract}

Keywords Education Industry, Customer Value, Medical Schools

\section{Introduction}

In academic institutes, students' motivations have been gaining considerable attention in the past few years $[1,2]$, and can be attributed to mainly two factors. First, there are studies documenting that having higher postgraduate degrees leads to higher future income. This attracts many people in the younger generations to pursue higher education, whatever the cost, and many have parents able to provide extensive support. Second, governments and organizations offer various types of scholarships for national or international studies, often covering a specific field, such as engineering, medical, and others [2]. For instance, a recent study shows that the choice of a university is determined by vocational rather than economic or image-based preferences [3].

The college of Applied Medical Sciences (AMS), for whom this study was undertaken, is affiliated with Taibah University institutes in Madinah, Saudi Arabia [4]. It is a tuition-free government institute. The current issue in many institutes is that most students choose the medical fields-medicine, pharmacy, nursing, rehabilitation, and dentistry. Initially, we presumed that students avoided enrolling in institutes with low employment rates following graduation. However, we found that low employment rates are also a problem in highly desirable institutes in certain fields, such as pharmacy and dentistry. Therefore, the current study focuses on this issue and provides a framework to motivate students' choices among different medical schools as a part of Vision 2030 transformation, the Saudi government's ambitious ten-year plan for development. 
In order to understand this issue in depth, we present a brief background of the process of choosing institutes and specialties. Students who have just graduated from high school enter Taibah University for their first year, which is a general requirement for all students. They study English, physics, mathematics, chemistry and other general courses. Their GPA from that first year is averaged with their GPA from high school, they choose the faculty (institute) and specialty they prefer, and they are ranked based on their GPA for entry into the computerized system. When the computer reaches their rank, it will look into their choices to find the first available place matching their preferences. In our case, most students have lower GPAs compared to other medical institutes. We believe two reasons may explain this phenomenon. First, students have no information about the future for graduates of our institute. Second, students tend to consult with current students who may discourage them from choosing our institute.

It is worth noting that at least half the undergraduate students have one fixed choice, and if they are not accepted to that program, they will opt for a private school or traveling abroad to study [5]. This case is observed more often among students wanting to enter medical or dental school [6]. There are many factors that lead students to have only one choice in mind, such as the influence of a parent who is a doctor or dentist, the prestige of the profession, and the guarantee of employment [7]. One study found that $46 \%$ (221 of 447 students) listed dentistry as their first choice [8]. These data are very useful for our study as we believe these single-minded students will yield less relevant data for our purposes. Therefore, we will look into how to motivate Taibah University students to choose the Applied Medical Sciences Institute as their first choice among potential medical schools.

\section{Materials and Methods}

Porter's five-forces analysis was utilized to assess this study [9]. In comparing government universities in Saudi Arabia, the threat of new competitors is moderate due to high capital costs related to the physical infrastructure, advertising, and promotion. Fixed costs (such as the academic staff) will be high too. The bargaining power of suppliers is relatively low because universities depend mainly on government support. The bargaining power of buyers (customers) is also low because students prefer government universities to private. With respect to employers and business customers, their bargaining power is high, as customers accept competent applicants who have graduated from any school or university. The threat of product substitution is also relatively low because distance learning and short courses do not meet most job requirements. Hence, the demand for university degrees is expected to continue in the long term. Competitive rivalry in the industry is high as there are many well-established universities ranked as high as the world's best universities. A Balanced Scorecard model was used to analyze the performance management tools for this study, as described previously $[10,11]$.

\section{Results}

In order for this work to succeed, we need the full support and cooperation of the decision makers. For this study, the decision makers include the Dean of AMS and the administrator of the institute teaching the first-year students (prospective customers). The role of the Dean of AMS is to encourage professors and staff to actively participate and to ensure the availability of various resources (classrooms, labs, equipment, funds, etc.). The role of the administrator of the first-year institute is to facilitate access to students and to ensure the availability of required classrooms. In addition, a team will be formed to include people from the school (professors, lab assistants, etc.) and volunteers from senior students and recent graduates who are enthusiastic about the specialty and believe in the study's objectives.

As shown in Figure 1, applying Porter's five-forces analysis (the model of competition) to the college of Applied Medical Sciences at Taibah University revealed the following salient points. First, as to intra-industry rivalry, rivals include the schools of medicine, pharmacy, nursing, rehabilitation medicine, and dentistry. Second, the threat of new competitors includes medical schools in other government and private universities in Saudi Arabia and international universities [12]. Third, the threat of product substitution comes from training programs in the private sector offering short courses and diplomas and from scholarships to study abroad.

It is important to underscore that this study on strategies to attract the best students to enroll in AMS has the potential to exert an invaluable impact on achieving the school's mission, which is two-fold: First, to prepare national graduates able to keep up with technological advances and services in the field of Applied Medical Sciences, thereby improving the quality of healthcare and disseminating health awareness. Second, to promote direct scientific research into solving environmental problems. These endeavors will foster the role of the college in community service.

Despite the aforementioned plans, we expect to face many challenges. For instance, we foresee objections such as: we do not know our students (customers), we have many different types of students, it is too difficult, we do not have the time and resources, we do not have the skills, and we are a monopoly (being the only government university in the city of Madinah). To overcome these challenges, we will hold multiple group discussions and try to educate the key players about the importance of attracting excellent students with high GPAs to our 
institute. Achieving that goal will have several significant impacts, some of which can be realized in the short term, such as greater professional satisfaction for professors, while others will be observed longer term, such as justification to open innovative labs to keep up with excellent students - the students who will continue to be excellent after graduation for which AMS can take credit and benefit from the consequent prestige.

\section{Porter's five forces analysis: Model of Competition Medical School's Industry: Medical Schools at Taibah University \\ - Medical Schools in other \\ Threats of new Entrants \\ Bargaining \\ Power of \\ Suppliers \\ - Government \\ - Faculty and Staff \\ - Equipment and Service \\ - Alumni \\ - Business and Foundations \\ Government Universities in Saudi Arabia. \\ - Medical Schools in Private Universities. \\ Medical Schools in International \\ Intra-industry Rivalry \\ Strategic Business Unit (SBU): \\ AMS School at Taibah University \\ Rivalry: the School of Medicine, \\ Pharmacy, Nursing, Rehabilitation \\ Medicine and Dentistry.

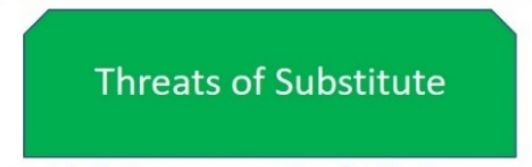 \\ - Training companies (offering short-courses and Diploma). \\ - Scholarships to study abroad. Universities.

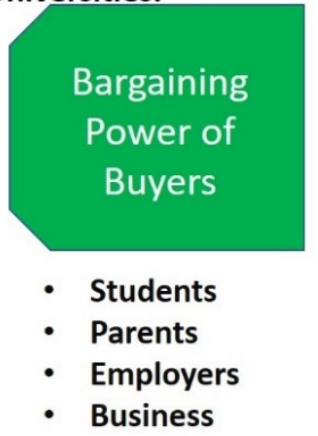

Figure 1. Porter's five forces analysis: Model of Competition for the college of Applied Medical Sciences at Taibah University.

To offer an excellent undergraduate programs in the field of Applied Medical Sciences in Saudi Arabia

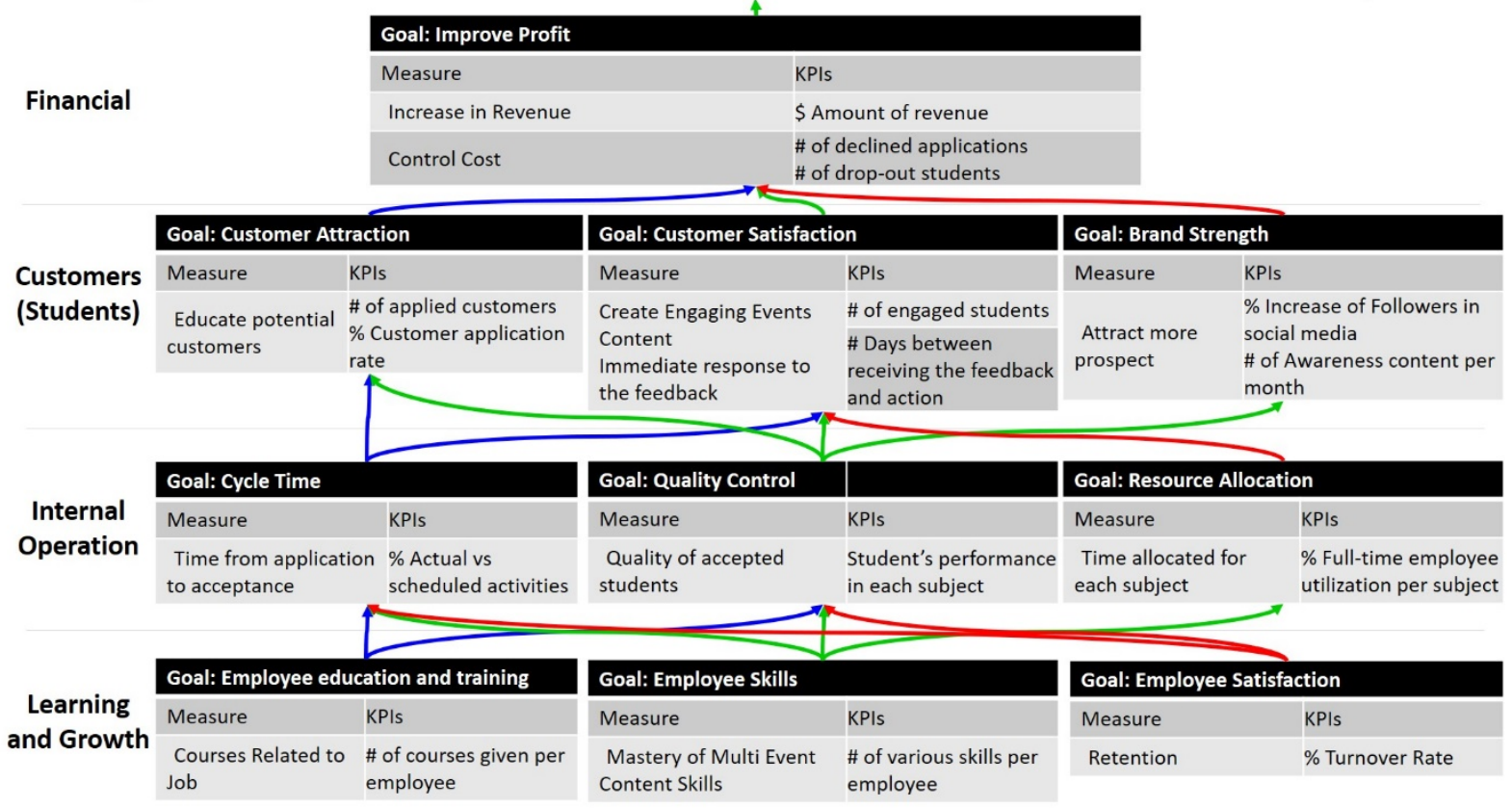

Figure 2. Balanced Scorecard model to offer an excellent undergraduate program in the field of Applied Medical Sciences at Taibah university. 
Next, the Balanced Scorecard model was utilized to make more effective assessments of the time, energy, and money required to attract customers, in our case undergraduate students, and to deliver services on a larger and more efficient scale. As shown in Figure 2, the goal of the financial aspect is to improve profit. Two main things will be evaluated: first, measuring the anticipated increase in revenue, and second, measuring costs that should be controlled - the number of declined applications and the number of students who drop out. It is not entirely unexpected that, at least in the first year, we could observe a high number of declined applications and/or drop-outs (around a third of the cohort). Our main objective is to establish a sustainable growth rate at which the maximum rate can grow without depleting our financial resources. It is highly likely that we will need to alter our financial policies based on the information available for analysis after the first and second years. Looking at customer appeal and satisfaction as well as strengthening the brand (i.e., the reputation of the undergraduate program), the aim is to explore how to attract more prospective customers, how to educate potential customers, and how to create the content for engaging events. Eventually, the institute will be oriented toward customer satisfaction. Internal operation is the next part of our Balanced Scorecard. The method is to look into the time cycle, quality control, and resource allocation. To achieve the goals, we will be measuring the time from application to acceptance, the quality of accepted students, and the time allocated for each subject. Finally, we must look at learning and growth. The goal here is to examine employee education, training, skills, and satisfaction. To achieve these goals, our aim is to implement courses closely related to the job, the mastery of multi-event content skills, and employee retention.

\section{Discussion}

The number of universities (government and private) in the Saudi Arabian education industry has increased in the last few years. Saudi Arabia accounts for the majority of universities in the Middle East and North African region [13]. It is well-known that the relation between universities and their customers (mainly students) is a life-long relationship. It starts with attracting talented students to become part of the university, followed by the experience of the students during their studies, and maintaining a life-time link as alumni of the university who can be expected to support the university in various ways (e.g., financial support and continuous contact with the university, often offering its students training during study and job opportunities after graduation). The concept of customer value is not new; however, it has gained more attention in recent years. This increasing attention is not limited to commercial companies - it extends to academic institutes and universities [14].

Academic institutes can be defined as enterprises that offer undergraduate and postgraduate degrees. It can be owned and administered by government or by private companies. A university can have many institutes, each one specializing in one domain, and they may have different departments. For example, the Applied Medical Sciences institute specializes in para-medical fields, such as laboratory medicine, radiology, and so on. Therefore, this institute will have departments relating to those specialties. To avoid possible confusion, the terms institute, college, and faculty are used interchangeably but refer to the same thing.

The Saudi Arabian education industry is forecast to continue improving in the rankings of its educational institutions and to add more universities, including renowned international universities, by 2030. In the last few years, the number of new institutes has increased, creating competition among both old and new institutes in attracting fresh high school graduates [5, 15]. Many institutes recognize that their main marketing tool is customer value, as evidenced by a strong bond between the institute and its current and former students - when they are successful in their studies and in their new careers, participating in alumni activities offered by the institute can be a mutually fulfilling and rewarding experience for them and the university. The growing competition among educational institutes and universities requires effective strategies to improve outcomes and competitiveness that can make the institute as unique as possible to attract students. This may include expanding the institute [16]. A recent study provides tools that enhance a university's brand image and reputation through customer value co-creation behavior [15].

The Balanced Scorecard model was applied to formulate an excellent undergraduate program in the field of Applied Medical Sciences at Taibah University. The appropriate application of this model will greatly enhance predictions about the future and achieving the institute's mission and vision [10]. We strongly believe that improving internal operations will lead to increased profits and assets turnover.

This study offers the following two recommendations: First, in-depth analyses similar to this one should be repeated annually. Second, the concept of customer value needs to be promoted at both the school and the university level. It is important to highlight that the majority of the proposed methodologies to positively impact the future of healthcare can be achieved through the utilization of this framework. For instance, Albala et al. proposed a Medical Maker curriculum to foster creativity in medical students [17]. Another promising course was proposed by Pan et al. to enrich a variety of the aspects of interpersonal communication and negotiation [18].

In conclusion, although customer value is known to be relevant for private schools, it has gained considerable 
attention in recent few years with regard to government schools. It is well-known that the relationship between universities and their customers (mainly students) is a life-long connection. It starts with attracting the best students to become part of the university, followed by the students' experience during their studies, and is maintained for a life-time as alumni who can be expected to support the university in various ways. Customer value in the education industry, especially universities, needs to be improved and included as a key performance indicator for schools and universities. Implementing excellent strategies to improve customer value will positively impact our institute.

\section{Conflict of Interest}

The author discloses no potential conflicts of interest.

\section{Funding}

This project was self-funded.

\section{REFERENCES}

[1] Goel S, Angeli F, Dhirar N, Singla N, Ruwaard D. What motivates medical students to select medical studies: a systematic literature review. BMC medical education. 2018;18(1):16

[2] Wu H, Pei L, Li S, Jiang C. Medical career expectations of academically talented high school students: a nationwide cross-sectional study in China. BMC medical education. 2020;20(1):166

[3] Bartkute D. Lithuanian students' choice of university: a consumer value approach. European Journal of Higher Education. 2017;7(2):173-87.

[4] Alzalabani AA, Eltaher SM. Perceptions and reasons of E-cigarette use among medical students: an internet-based survey. The Journal of the Egyptian Public Health Association. 2020;95(1):21.

[5] Alzerwi NAN. Effects of Grit on the Academic Performance of Medical Students: A Cross-Sectional Study at Majmaah University. Advances in medical education and practice. 2020;11:419-25.

[6] Bin Abdulrahman KA, Saleh F. Steps towards establishing a new medical college in the Kingdom of Saudi Arabia: an insight into medical education in the Kingdom. BMC medical education. 2015;15:85-

[7] Fallatah HI, Soo Park Y, Farsi J, Tekian A. Mentoring Clinical-Year Medical Students: Factors Contributing to Effective Mentoring. Journal of medical education and curricular development. 2018;5:2382120518757717-.

[8] Al-Bitar ZB, Sonbol HN, Al-Omari IK. Reasons for choosing dentistry as a career by Arab dental students. European Journal of Dental Education. 2008;12(4):247-51.

[9] Porter ME. The five competitive forces that shape strategy. Harvard business review. 2008;86(1):78-93, 137.

[10] Huntington J, Dick JF, 3rd, Ryder HF. Achieving educational mission and vision with an educational scorecard. BMC medical education. 2018;18(1):245.

[11] Kaplan RS, Norton DP. The balanced scorecard--measures that drive performance. Harvard business review. 1992;70(1):71-9.

[12] Telmesani A, Zaini RG, Ghazi HO. Medical education in Saudi Arabia: a review of recent developments and future challenges. Eastern Mediterranean health journal = La revue de sante de la Mediterranee orientale $=$ al-Majallah al-sihhiyah li-sharq al-mutawassit. 2011;17(8):703-7.

[13] Albejaidi F, Nair KS. Building the health workforce: Saudi Arabia's challenges in achieving Vision 2030. The International journal of health planning and management. 2019;34(4):e1405-e16.

[14] Rajeh N, Grant J, Farsi J, Tekian A. Contextual Analysis of Stakeholder Opinion on Management and Leadership Competencies for Undergraduate Medical Education: Informing Course Design. J Med Educ Curric Dev. 2020;7:2382120520948866.

[15] Foroudi P, Yu Q, Gupta S, Foroudi MM. Enhancing university brand image and reputation through customer value co-creation behaviour. Technological Forecasting and Social Change. 2019;138:218-27.

[16] Cirillo N, AlShwaimi E, Prime SS, Al-Hayani A. CREATING: a sustainable plan for biomedical higher education in Saudi Arabia. Phase I. International journal of health sciences. 2015;9(1):93-103.

[17] Albala L, Bober T, Mallozzi M, Koeneke-Hernandez L, Ku B. Design-thinking, making, and innovating: Fresh tools for the physician's toolbox. Universal Journal of Educational Research. 2018;6(1):179 - 83.

[18] Pan AJ, Pan AJ, Leary KR. Professional Interactions: Negotiation and Expression for Future Physicians and Healthcare Providers. Universal Journal of Educational Research. 2017;5(11):2101-6. 